\title{
The Efficiency and Profitability of the Modular Multilevel Battery for Frequency Containment Reserve
}

\author{
Markus Förstl \\ Technical University of Munich \\ Munich, Germany \\ markus.foerstl@tum.de \\ Holger Hesse \\ Institute for Electrical Energy Storage Technology \\ Technical University of Munich \\ Munich, Germany \\ holger.hesse@tum.de \\ Andreas Jossen \\ Institute for Electrical Energy Storage Technology \\ Technical University of Munich \\ Munich, Germany \\ andreas.jossen@tum.de
}

Institute for Electrical Energy Storage Technology STABL Energy G

Munich, Germany

\author{
Nam Truong \\ Marc Möller
}

bH Inst

(1)

\author{
Arthur Singer \\ STABL Energy GmbH \\ Munich, Germany
}

\author{
Technical University of Munich \\ Munich, Germany \\ marc.moeller@tum.de \\ Thomas Weyh \\ Institut für Elektrische Energieversorgung \\ Universität der Bundeswehr München \\ Munich, Germany \\ thomas.weyh@unibw.de
}

\begin{abstract}
The modular multilevel battery (M2B) is a novel approach to integrate battery storage into the electricity grid. This paper obtains the efficiency a nd fi nancial be nefits of a working prototype system, compared to conventional systems for frequency containment reserve (FCR). The efficiency i s determined with a low-level simulation that models the conduction losses on the circuit, the MOSFETs' switching and conduction losses, and the system consumption. The simulation model shows, that the efficiency i s s uperior $t$ oc onventional i nverters over the entire operating range. The operation for FCR shows a cost-reduction of $50 \%$ for transactions on the intraday market, resulting in a $72.9 \%$ higher net-profit after 10 years.

Keywords-inverter, power electronics, efficiency analysis, frequency control reserve
\end{abstract}

\section{INTRODUCTION}

\section{A. Motivation and research objective}

Conventional stationary battery energy storage systems (BESSs) usually consist of two major hardware parts: a highvoltage battery pack and a centralized converter. The battery pack consists of several modules that can be connected in a series-parallel configuration to achieve desired capacity and output voltage, depending on the project or customer specifications. The centralized converter is usually a two-level voltage source inverter operated with pulse width modulation [1-3].

While this configuration is simple and established, it has a few disadvantages. The failure of one module leads to the failure of the whole pack. Furthermore, conventional converters have maximum one-way efficiencies of around $98 \%$ [4] that drop rapidly in partial-load operation. Since many applications of stationary BESSs, such as grid ancillary services, operate in partial load, power electronics can be responsible for up to $50 \%$ of the total losses [5]. Furthermore, the large switching voltage of conventional two-level inverters introduces large total harmonic distortions that need to be filtered to comply with grid codes and standards, which is cost-intensive and decreases efficiency [2].

The modular multilevel battery (M2B) is a novel approach of integrating batteries into the grid with the promise of higher efficiency [6]. Its functionality is based on the concept of cascaded H-bridge converters. Previous work describes the functionality of the M2B in detail $[6,7]$. This work calculates the efficiency based on a semiconductor-level simulation model. With the obtained efficiency, we estimate the impact on the operation for a BESS providing frequency containment reserve (FCR) on the German market.

\section{B. System topology of the modular multilevel battery}

The investigated system topology differs from commercially available systems. The battery modules are not hard-wired to form a high-voltage battery pack that is connected to a central converter. Instead, the battery modules are connected to the M2B circuit. The battery modules are dynamically connected in series to generate a stepped output voltage to emulate the sine form of the grid voltage. Fig. 1 illustrates how the output voltage of the inverter is generated.

Switching losses are proportional to both the switching frequency and the squared switching voltage [8]:

$$
P_{\text {switch }} \propto f_{\text {switch }} \cdot V_{\text {switch }}^{2} \text {. }
$$



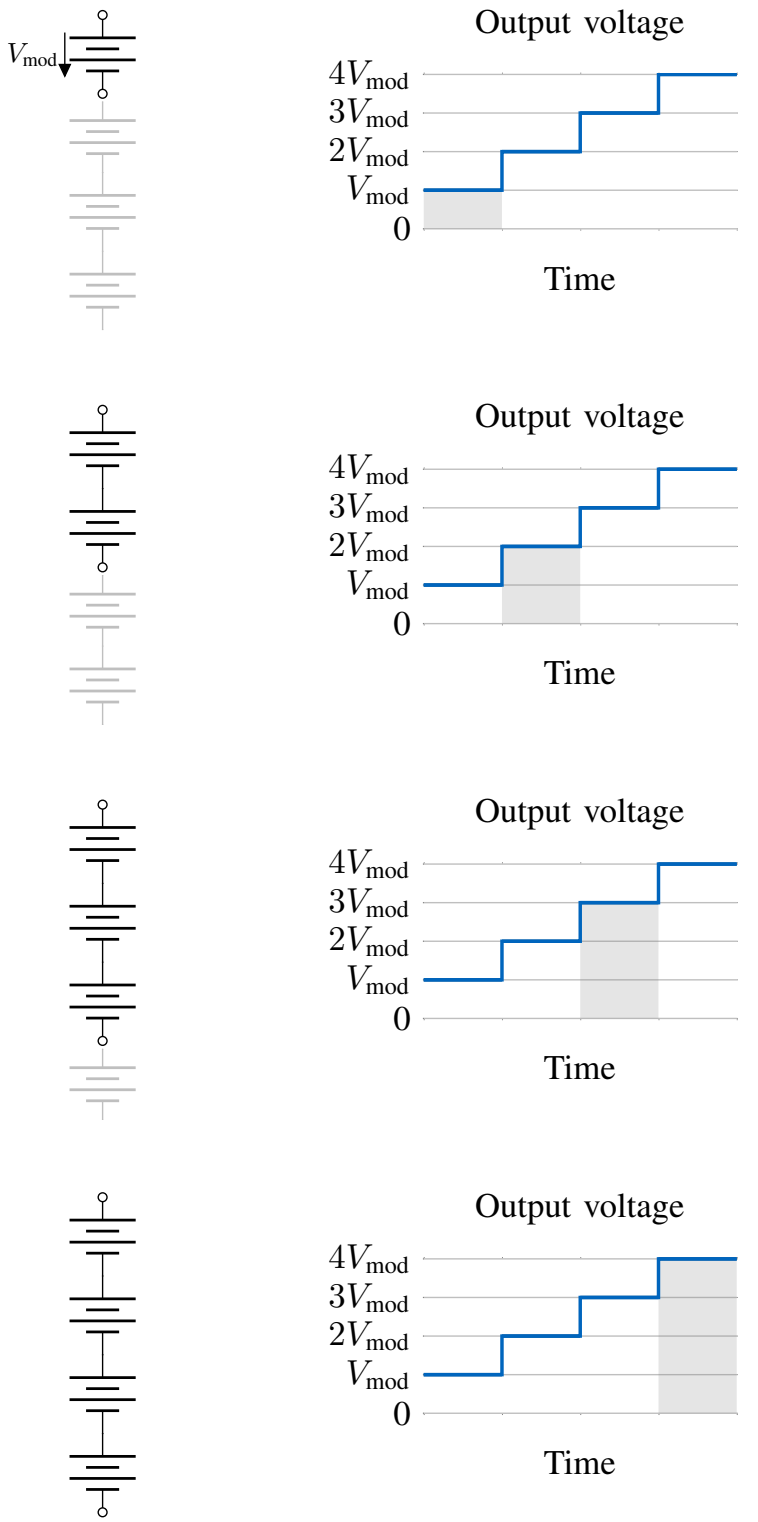

Figure 1: Illustration of operating principle of the dynamic series connection for four battery modules. Gray modules are bypassed. Black modules are active and supply the output voltage.

These are expected to be significantly reduced. The novel conversion method requires the MOSFETs to only switch with a frequency of $200 \mathrm{~Hz}$, instead of 8 to $12 \mathrm{kHz}$ switching frequency of the IGBTs in conventional inverters. In addition, the switching voltage is the voltage of a single battery module, which is usually below $60 \mathrm{~V}$, compared to the switching of about $800 \mathrm{~V}$ in today's systems.

Each M2B circuit attached to a battery module attains several states. The three relevant states for the standard operation are to bypass the battery, connect the battery module with a positive voltage, and to connect the battery module with a negative voltage. The output of the module is then $0 \mathrm{~V},+V_{\text {mod }}$,

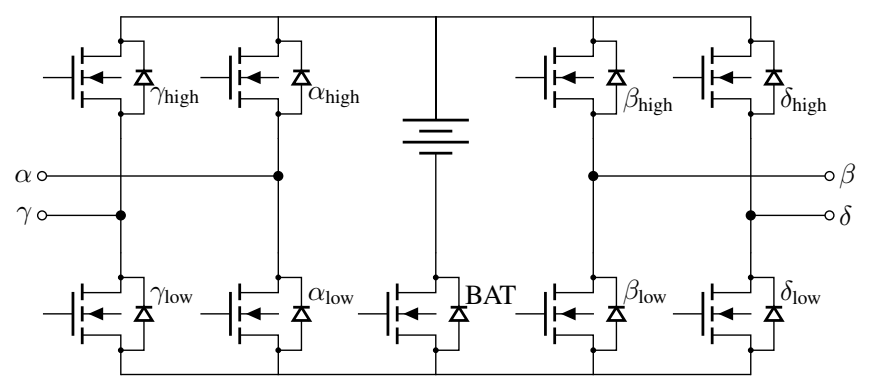

Figure 2: Topology of the M2B circuit

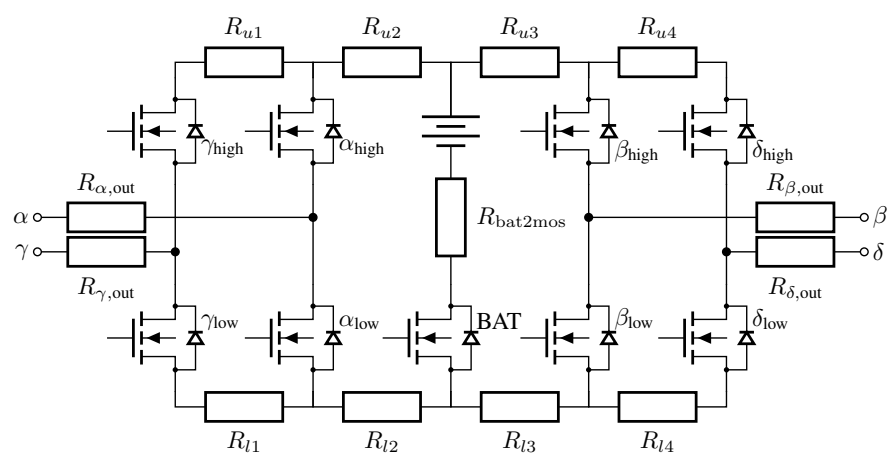

Figure 3: Implementation of one M2B circuit for the simulation model. The 13 resistors represent the resistances of the circuit board [11], which also contribute to the power losses.

and $-V_{\text {mod }}$, respectively. Fig. 2 shows the schematic of the M2B circuit. The connection of modules to one inverter leg and a BESS is described in [6].

\section{SYSTEM EFFICIENCY}

\section{A. Simulation model}

A simulation model is built with the "Plecs Blockset Toolbox" for MATLAB's Simulink software to obtain the losses of the system and calculate the efficiency of the inverter system. The model includes the conduction losses of the printed circuit board and the conduction and switching losses of the MOSFETs.

The MOSFET losses are modeled using a look-up table approach [9], using datasheet values obtained from the MOSFET's datasheet [10]. Conduction losses of the circuit board are modeled as resistances, which have of the current paths on the printed circuit board have been measured directly with a high-precision measurement [11]. Fig. 3 shows the resulting implementation of one M2B module.

The simulated BESS is a eight-module M2B connected to the grid, modeled as a AC voltage source with an impedance. Between the BESS and the grid is a line filter. Table I gives an overview of the parameters for the simulation model.

The simulation does not include the self-consumption of the electronics. As this is more dependent on the specific design of the hardware, the consumption has been measured on the actual hardware. We measured the consumption of the master 
Table I: Parameters of the low-level simulation model

\begin{tabular}{|c|c|c|}
\hline Parameter & Value & Unit \\
\hline \multicolumn{3}{|l|}{ Simulation model } \\
\hline Simulation time & 1 & $\mathrm{~s}$ \\
\hline Sample time & 40 & $\mu \mathrm{s}$ \\
\hline Number of modules & 8 & \\
\hline \multicolumn{3}{|l|}{ Grid and grid connection components } \\
\hline Grid frequency & 50 & $\mathrm{~Hz}$ \\
\hline Grid voltage (RMS) & 230 & $\mathrm{~V}$ \\
\hline Line filter inductance & 3 & $\mathrm{mH}$ \\
\hline \multicolumn{3}{|l|}{ Battery module } \\
\hline Open-circuit voltage & 47.5 & $\mathrm{~V}$ \\
\hline Internal resistance & 24 & $\mathrm{~m} \Omega$ \\
\hline \multicolumn{3}{|l|}{ MOSFET } \\
\hline Maximum drain-to-source voltage & 100 & $\mathrm{~V}$ \\
\hline Maximum drain current & 300 & $\mathrm{~A}$ \\
\hline Reverse-recovery charge (body diode) & 316 & $\mathrm{nC}$ \\
\hline \multicolumn{3}{|l|}{ Circuit board resistances } \\
\hline$R_{u 1}$ and $R_{u 4}$ & 0.74 & $\mathrm{~m} \Omega$ \\
\hline$R_{u 2}$ and $R_{u 3}$ & 0.55 & $\mathrm{~m} \Omega$ \\
\hline$R_{l 1}$ and $R_{l 4}$ & 0.49 & $\mathrm{~m} \Omega$ \\
\hline$R_{l 2}$ and $R_{l 3}$ & 0.59 & $\mathrm{~m} \Omega$ \\
\hline$R_{\alpha, \text { out }}$ & 0.18 & $\mathrm{~m} \Omega$ \\
\hline$R_{\beta, \text { out }}$ & 0.25 & $\mathrm{~m} \Omega$ \\
\hline$R_{\gamma, \text { out }}$ & 0.18 & $\mathrm{~m} \Omega$ \\
\hline$R_{\delta, \text { out }}$ & 0.26 & $\mathrm{~m} \Omega$ \\
\hline$R_{\text {bat } 2 \operatorname{mos}}$ & 0.15 & $\mathrm{~m} \Omega$ \\
\hline
\end{tabular}

Table II: Power consumption of system components

\begin{tabular}{lr} 
Component & Power consumption \\
\hline Master controller & $2.595 \mathrm{~W}$ \\
Current sensor & $1.215 \mathrm{~W}$ \\
Control board & $1.491 \mathrm{~W}$
\end{tabular}

controller, the current sensors, and the control boards of one M2B module. Hence, the system consumption of an M2B system with $m$ modules (in total) and designed for a $n$-phase operation can be calculated by

$P_{\text {System }, m, n}=m \cdot P_{\text {Control board }}+n \cdot P_{\text {Current sensor }}+P_{\text {Master Controller }}$.

\section{B. Results and discussion}

Fig. 4 shows the resulting efficiency curve over the normalized output power of the M2B (blue) compared to the reference inverter efficiency (green) [12].

The simulation results confirm the hypothesis that the switching losses are significantly reduced. While the system consumption, conduction losses of the MOSFETs, and the conduction losses on the printed circuit boards are in the same magnitude, the switching losses are negligible in comparison. They are lower than $1 \%$ of the overall losses in all operation points. Fig. 5 shows the proportional shares of the loss mechanisms in relation to the overall losses.
Efficiency in \%

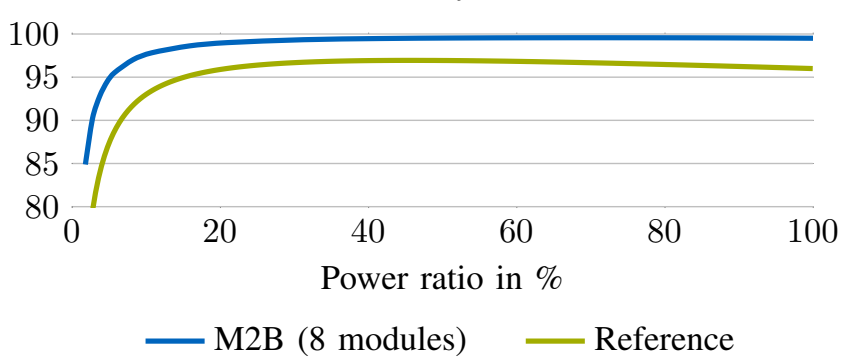

Figure 4: Simulated efficiency of the M2B system with eight modules compared to the reference system [12]. For the whole operating range, the M2B shows higher efficiencies.

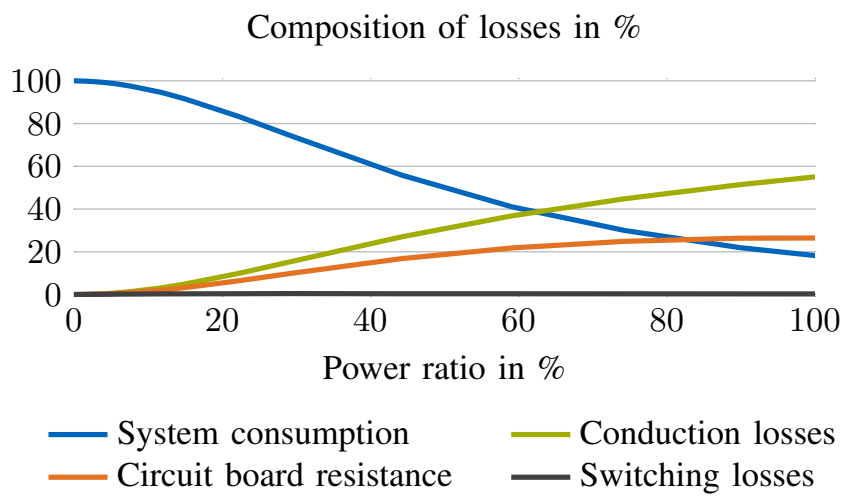

Figure 5: Composition of losses depending on power ratio.

\section{CASE STUDY: FREQUENCY CONTAINMENT RESERVE}

\section{A. Assumptions}

FCR is one of the two most popular applications for BESSs in Germany [13]. FCR is a grid-service for any grid participant to reduce or increase the net power output based on the grid frequency. The grid frequency serves as value to determine the balance between load and generation that needs to be maintained to keep the power system stable. BESSs already provide the major share of FCR, resulting in a larger supply than demand. Increasing renewable energy generation, however, also increases the demand.

The measurement of the ENTSO-E grid's frequency of 2014 [14] is used to determine the necessary output power of the BESS. The utilized degrees of freedom for SOC management of the BESS are use of the frequency deadband, over fulfillment of the power request, and the participation in the German intraday market (IDM), where the BESS operator purchases or sells energy to set the SOC to stay within a valid operating range. The IDM market prices of 2018, obtained from the European Power Exchange [15] are used for the simulation. For the reserved FCR, the corresponding average capacity price retrieved by the German TSOs for 2018 was used [16]. Furthermore, we assume that the BESS participates at all tenders in the year. 
Table III: Parameters for the FCR case study.

\begin{tabular}{lrll} 
Parameter & Value & Unit & Ref. \\
\hline Simulation parameters & & & \\
$\quad$ Simulation time & 1 & year & \\
$\quad$ Sample time & 1 & $\mathrm{~s}$ & \\
Technical parameters & & & \\
$\quad$ Nominal energy capacity & 1.5 & $\mathrm{MWh}$ & {$[17]$} \\
$\quad$ Nominal power & 1.8 & $\mathrm{MW}$ & {$[17]$} \\
Prequalified power & 1 & $\mathrm{MW}$ & {$[17]$} \\
Maximum power for IDM & 0.5 & $\mathrm{MW}$ & \\
Grid frequency & 50 & $\mathrm{~Hz}$ & \\
Dead band & \pm 10 & $\mathrm{mHz}$ & \\
Economic parameters & & & \\
$\quad$ Fixed battery costs & 1723 & EUR & {$[3]$} \\
$\quad$ Variable battery costs & 752 & EUR/kWh & {$[3]$} \\
$\quad$ Total investment costs $\left(C_{\text {inv }}\right)$ & 1129723 & EUR & \\
$\quad$ Maintenance costs & $0.02 \cdot C_{\text {inv }}$ & EUR/year & {$[17]$} \\
Operational costs & 4000 & EUR/year & {$[17]$} \\
Depreciation period & 20 & years & \\
Inflation rate & 2 & $\%$ & {$[18]$} \\
$\quad$ Nominal interest rate & 4 & $\%$ & {$[18]$}
\end{tabular}

Technical and economic parameters for the case study are shown in Table III.

\section{B. Simulation model}

The simulation tool SimSES [19] is used to compute the BESS in the application of FCR. It calculates the BESS operation on a technical level: the respective output power of the BESS depending on the frequency every second. The system losses and energy consumption are considered, as well as the SOC of the BESS. The battery cell losses are modeled with an equivalent circuit model that includes the open-cell voltage (OCV) and the inner resistance, which resembles a state-of-the-art lithium ion battery with LFP cathode chemistry [20]. More dynamic components, such as RC-elements are not necessary because the simulation's sample time of 1 second does not capture more dynamic battery behavior.

SimSES allows for calculation of technological and economic key performance indicators, such as round-trip efficiency, state of health $(\mathrm{SOH})$, and net present value (NPV) of costs and revenue.

Two parameter sets are compared: a conventional BESS and a BESS equipped with the M2B inverter and its respective efficiency curve.

The reference converter is modeled via an efficiency curve described by Notton et al. [12] and is calculated by

$$
\eta_{\text {ref }}=\frac{p}{p+p_{0}+k p^{2}}
$$

where $p$ is the power ratio and $p_{0}$ and $k$ are constants calculated by

$$
\begin{aligned}
p_{0} & =\frac{1}{99}\left(\frac{10}{\eta_{10}}-\frac{1}{\eta_{100}}-9\right) \text { and } \\
k & =\frac{1}{\eta_{100}}-p_{0}-1,
\end{aligned}
$$

Table IV: Parameters of the converter models for the FCR simulations.

\begin{tabular}{lrrrrr} 
& \multicolumn{2}{c}{ Reference [12] } & \multicolumn{3}{c}{ M2B } \\
Parameter & $p_{0}$ & $k$ & $k_{0}$ & $k_{1}$ & $k_{2}$ \\
\hline Value & 0.0072 & 0.0345 & 0.003189 & -0.007566 & 0.009991
\end{tabular}

Histogram of the delivered AC power in \%

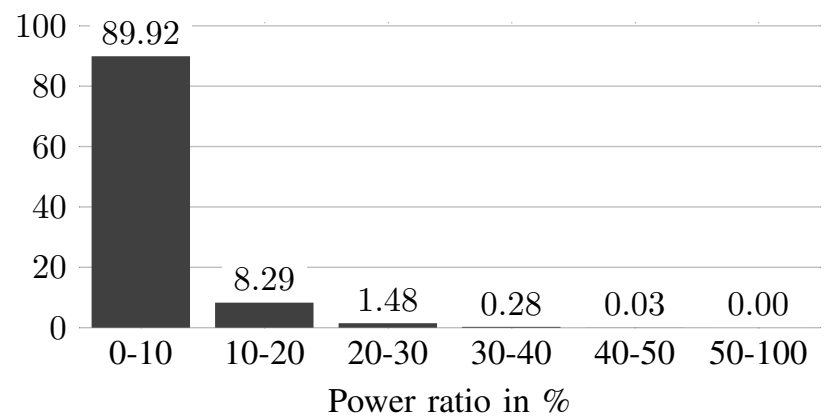

Figure 6: Frequency distribution of the delivered AC power of the storage systems.

where $\eta_{10}$ and $\eta_{100}$ are the efficiencies at $10 \%$ and $100 \%$ of the maximum power. [12]

The M2B efficiency is also fitted mathematically, but with a different equation

$$
\eta_{\mathrm{M} 2 \mathrm{~B}}=\frac{p}{p+k_{0}+k_{1} p+k_{2} p^{2}},
$$

according to [21], which yields a more precise fit. Again, $p$ is the power ratio; $k_{0}, k_{1}$, and $k_{2}$ are mathematical coefficients, which were determined by a non-linear least squares approach.

Table IV shows the parameters for both converter models.

\section{Technical results of the case study}

With M2B's efficiency, the BESS achieves a round-trip efficiency of $90.7 \%$ compared to the reference system's $79.6 \%$. Looking at the power distribution of the delivered AC power for both systems in Figure 6, it becomes clear that FCR operates below $30 \%$ of the nominal power for more than $99 \%$ of the time.

Together with the relative conversion efficiency difference of the M2B and the reference, shown in Figure 7, we can explain the high difference of the round-trip efficiency. Almost $90 \%$ of the delivered $\mathrm{AC}$ power lie within the range of 0 to $10 \%$, where, on average, M2B efficiency is $13.5 \%$ higher than the reference's.

\section{Economic results of the case study}

Fig. 8 shows all cash flows for the simulated year. The expenditure of M2B through IDM transactions is $53.9 \%$ lower than those of the reference. Revenue through FCR is the same for both systems as they can reserve their prequalified power for the whole time. The cost savings on the IDM yield an annual cash flow of 99669 EUR for the M2B, which is $15.8 \%$ higher than the reference. 
Relative efficiency difference

between M2B and reference in \%

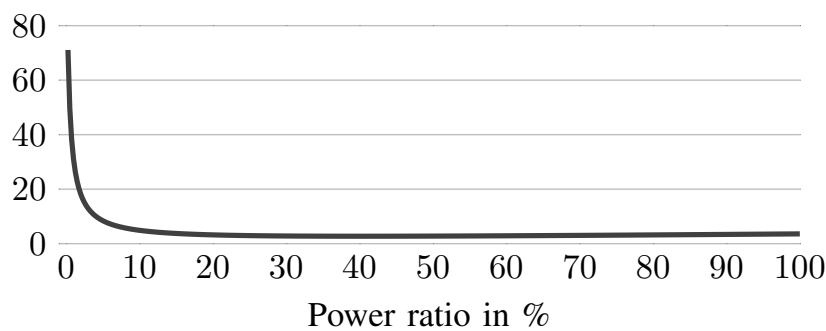

Figure 7: Relative efficiency difference between M2B and the reference system.

Cash flows for one year in thousand EUR

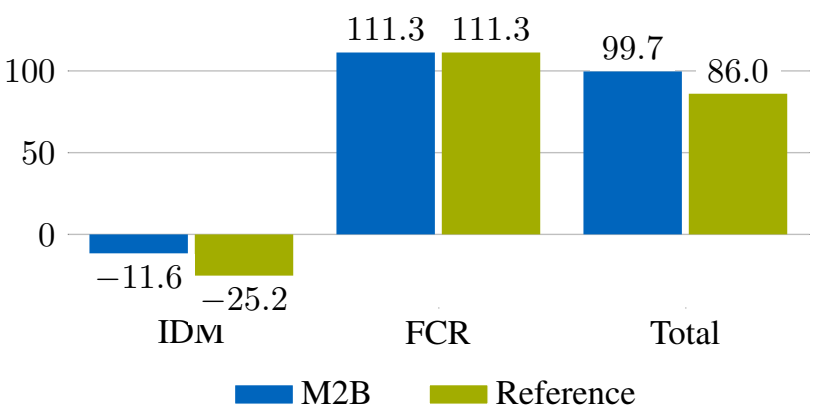

Figure 8: Cash flows for the M2B and reference converter topology for one year. With M2B's efficiency, the BESS saves more than $53.9 \%$ on IDM transactions. Revenue for FCR is the same for both systems; they can reserve their prequalified power for the whole time. The IDM savings for M2B yield an increase in cash flow of $15.8 \%$.

The reason for the cost savings is the higher efficiency of the M2B system, whereby differences in partial load operation especially come into play. Due to the higher efficiency, less energy is lost during charge and discharge. Hence, less energy needs to be purchased through IDM transactions to stay within the valid operating range. This leads to reduced costs and in turn to a higher annual cash flow.

We discount the cash flow for 20 years assuming that each year's revenue is the same and use the NPV method to determine the time it takes for the project to become profitable. After ten years, the NPV is -284909 EUR and -436807 EUR for M2B and the reference, respectively.

Fig. 9 shows the NPV for every other year of operation. After 20 years, the reference accomplishes an NPV of 461606 EUR. The M2B's NPV is 797957 EUR, which marks a relative increase of $72.9 \%$.

\section{CONCLUSION}

This paper quantifies the efficiency of the M2B topology and compares it to conventional converters, based on references from academic literature.
A low-level component simulation model is used to obtain the efficiency curve of the converter. The results reveal a higher efficiency c ompared t o c onventional c onverters, e specially in partial-load operation. The high efficiency can be attributed to low switching frequency and using low-resistance MOSFETs as switches. Furthermore, the modularity of the M2B leads to a smaller switching voltage. Therefore, switching losses do not play a significant $r$ ole. $C$ onduction a nd $\mathrm{c}$ ircuit path resistances are the primary loss mechanisms for high powers, while system consumption is dominant for low powers.

Based on the obtained efficiency curve, we performed a case study for estimating the performance on a system level. For this, we simulated a BESS providing FCR and performing IDM transactions for one year two times: with the M2B inverter efficiency and with a reference efficiency representing an inverter with low load-independent and load-dependent losses. M2B's efficiency y ielded in b etter $\mathrm{p}$ erformance both technically and economically. The round-trip efficiency of the BESS with M2B efficiency w as $90.7 \%$, w hich is m ore than ten percentage points higher than the round-trip efficiency of the reference $(79.6 \%)$. The M2B saves more than $50 \%$ on IDM transactions, which yielded in a cash flow i ncrease of over $15 \%$ compared to the reference.

The simulations reveal that the M2B has a higher efficiency compared to conventional battery inverters. Especially the high partial-load efficiency $c$ an be a ttributed to the economic savings of the M2B for the FCR scenario.

\section{OUTLOOK}

Further work will focus on verifying the high efficiency with system measurements. Additionally, a comparison with state-of-the-art commercial converters is necessary. Statements about the impact on battery health of the M2B were not made within the scope of this work. Therefore, future work will also investigate longer simulation periods and impact on battery health. The economic performance for other applications such as peak shaving would also be an interesting topic. Lastly, future work can estimate the possible reductions of carbon emissions on a global scale.

\section{ACKNOWLEDGMENT}

The authors thank the Federal Ministry for Economic Affairs and Energy for their financial support via the EffSkalBatt project (FKZ: 03ET6148). The responsibility for the content of this publication lies with the authors. 
Development of NPV over 20 years in thousand EUR

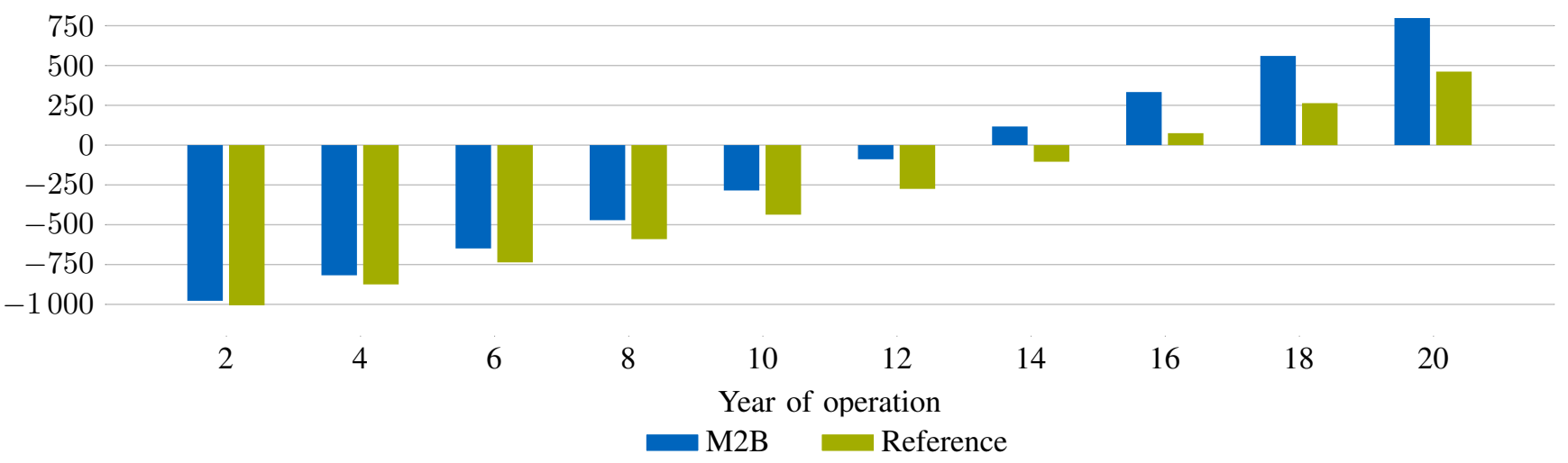

Figure 9: NPV for both inverter topologies for every other year of operation.

\section{REFERENCES}

[1] T. Soong and P. W. Lehn. "Evaluation of Emerging Modular Multilevel Converters for BESS Applications". In: IEEE Transactions on Power Delivery 29.5 (Oct. 2014), pp. 2086-2094. ISSN: 0885-8977. DOI: 10. 1109/TPWRD.2014.2341181.

[2] G. Wang et al. "A Review of Power Electronics for Grid Connection of Utility-Scale Battery Energy Storage Systems”. In: IEEE Transactions on Sustainable Energy 7.4 (Oct. 2016), pp. 1778-1790. ISSN: 19493029. DOI: $10.1109 /$ TSTE.2016.2586941.

[3] Holger C. Hesse et al. "Lithium-Ion Battery Storage for the Grid-A Review of Stationary Battery Storage System Design Tailored for Applications in Modern Power Grids”. In: Energies 10.12 (2017). ISSN: 1996-1073. DOI: 10.3390/en10122107.

[4] Silke Allebrod, Roman Hamerski, and Rainer Marquardt. "New transformerless, scalable Modular Multilevel Converters for HVDCtransmission". In: 2008 IEEE Power Electronics Specialists Conference. IEEE, June 2008. DOI: 10.1109/pesc.2008.4591920.

[5] Michael Schimpe et al. "Energy efficiency evaluation of a stationary lithium-ion battery container storage system via electro-thermal modeling and detailed component analysis". In: Applied Energy 210 (Jan. 2018), pp. 211-229. DOI: 10.1016/j.apenergy.2017.10.129.

[6] Florian Helling et al. "The AC battery - A novel approach for integrating batteries into AC systems". In: International Journal of Electrical Power \& Energy Systems 104 (2019), pp. 150-158. ISSN: 0142-0615. DOI: https://doi.org/10.1016/j.ijepes.2018.06.047.

[7] Arthur Singer et al. "A Novel, Scalable, Low-Cost and High-Efficiency Battery Storage System Topology". In: The 13th International Renew able Energy Storage Conference 2019 (IRES 2019). Atlantis Press, 2019/11. ISBN: 978-94-6252-836-9. URL: https://www.atlantis-press. com/article/125923334.

[8] T. Okabe et al. "Characterization and Improvement-of Power MOSFET Switching Loss". In: INTELEC '83 - Fifth International Telecommunications Energy Conference. Oct. 1983, pp. 508-513.

[9] A. Kersten, E. Grunditz, and T. Thiringer. "Efficiency of Active Three-Level and Five-Level NPC Inverters Compared to a Two-Level Inverter in a Vehicle". In: 2018 20th European Conference on Power Electronics and Applications (EPE'18 ECCE Europe). Sept. 2018, P.1-P.9.

[10] MOSFET OptiMOS 5 Power-Transistor, $100 \mathrm{~V}$. Data sheet. Infineon Technologies AG, 2017, pp. 1-12. URL: https://www.infineon.com/ dgdl/Infineon - IPT015N10N5 - DS - v02\% 7B \% 5C \% 7D01 - EN.pdf? fileId=5546d4624a75e5f1014ac94680661aff (visited on Jan. 22, 2020)

[11] Arthur Singer. "Evaluierung einer modularen Umrichtertopologie zur Kombination von Batteriesystemen, Balancing-Systemen, Umrichtern und Ladeschaltungen". German. Dissertation. München: Bundeswehr University Munich, 2019.

[12] G. Notton, V. Lazarov, and L. Stoyanov. "Optimal sizing of a gridconnected PV system for various PV module technologies and inclinations, inverter efficiency characteristics and locations". In: Renewable Energy 35.2 (Feb. 2010), pp. 541-554. DOI: 10.1016/j.renene.2009. 07.013

[13] Peter Stenzel, Wilfried Hennings, and Jochen Linssen. "Energiespeicher 2016". German. In: BWK Energie (May 1, 2016). URL: https //www.ingenieur.de/fachmedien/bwk/energiespeicher/energiespeicher$2 /$.

[14] Transnet BW. Regelenergie Bedarf + Abruf. 2020. URL: https://www. transnetbw. de / de / strommarkt / systemdienstleistungen / regelenergie bedarf-und-abruf\#netzf2014 (visited on Feb. 12, 2020).

[15] European Power Exchange SE. 2020. URL: http://www.epexspot.com/ en.

[16] Deutsche Übertragungsnetzbetreiber. regelleistung.net. Internetplattform zur Vergabe von Regelleistung. 2020. URL: https:// www. regelleistung.net/ext/ (visited on Feb. 12, 2020).
[17] Johannes Fleer et al. "Price development and bidding strategies for battery energy storage systems on the primary control reserve market". In: Energy Procedia 135 (Oct. 2017), pp. 143-157. DOI: 10.1016/j. egypro.2017.09.497.

[18] Markus Förstl et al. "Assessment of residential battery storage systems and operation strategies considering battery aging". In: International Journal of Energy Research 44.2 (Nov. 2019), pp. 718-731. DOI: 10. 1002/er.4770.

[19] Maik Naumann et al. "SimSES: Software for techno-economic Simulation of Stationary Energy Storage System". In: Batterieforum Deutsch land 2017. Berlin: Unpublished, 2017. DOI: 10.13140/RG.2.2.13008 61449.

[20] Maik Naumann et al. "Analysis and modeling of calendar aging of a commercial LiFePO4/graphite cell”. In: Journal of Energy Storage 17 (June 2018), pp. 153-169. DOI: 10.1016/j.est.2018.01.019.

[21] G.A. Rampinelli, A. Krenzinger, and F. Chenlo Romero. "Mathematical models for efficiency of inverters used in grid connected photovoltaic systems". In: Renewable and Sustainable Energy Reviews 34 (June 2014), pp. 578-587. DOI: 10.1016/j.rser.2014.03.047. 